\title{
Peritonitis bacteriana espontánea por Listeria monocytogenes, en un paciente con cirrosis hepática. Caso clínico
}

\author{
Francisco Espinoza-Gómez ${ }^{1,2}, 0$ scar Newton-Sánchez ${ }^{1}$, \\ Valery Melnikov ${ }^{1}$, Luis Pinzón $\mathbf{S}^{2}$,a. \\ Spontaneous bacterial peritonitis \\ caused by Listeria in a patient \\ with cirrhosis. Case report
} \begin{abstract}
cattle and occasionally appear in humans, particularly pregnant women and immunocompromised individuals. Peritonitis by Listeria monocytogenes is a rare but dangerous condition that must be recognized early, since it requires a specific treatment. We report a 31 year-old male with alcoholic cirrhosis that developed ascites with abdominal pain and fever. The peritoneal fluid culture yielded Listeria monocytogenes. The patients was initially treated with cefotaxim and later with ampicillin and levofloxacin. The patient voluntarily abandoned treatment and died at home two weeks later (Rev Méd Chile 2006; 134: 1171-4).

(Key words: Ascites; Lysteria monocytogenes; Peritonitis)
\end{abstract}

Infections caused by Listeria monocytogenes are usually found in

Recibido el 2 de noviembre, 2005. Aceptado el 30 de marzo, 2006.

${ }^{1}$ Facultad de Medicina, Universidad de Colima, Colima, México. ${ }^{2}$ Hospital Regional Universitario de la Secretaría de Salud del Estado de Colima, México.

aQuímico Farmacobiólogo

L

a Listeria monocytogenes es un cocobacilo nerobio, Gram positivo no esporulado, móvil a temperatura ambiente, hemolítico y catalasa positivo, y que aumenta su aislamiento con la técnica de enriquecimiento en frío ${ }^{1}$; afecta fundamentalmente al ganado bovino y caprino. Existen siete especies de Listeria, pero sólo L ivanovii y L

Correspondencia a: Dr. Francisco Espinoza Gómez. Laboratorio de Salud Pública de la Facultad de Medicina, de la Universidad de Colima. Avenida Universidad 333, Colonia Las Víboras, Colima, Col. México. CP 28040. Teléfono- Fax: (52) 31231610 99. E mail: fespin@cgic.ucol.mx monocytogenes se consideran patógenas, siendo esta última de importancia en salud pública ${ }^{2}$. La prevalencia en la población general, en material fecal, es de 5-14\%2-5. L monocytogenes se ha asociado a infecciones perinatales con una tasa de 9 por cada 100.000 nacimientos y una mortalidad de $20-40 \%{ }^{6,7}$, en adultos representa una condición rara pero generalmente severa, que suele presentarse en personas inmunocomprometidas, con presentación inicial a nivel gastrointestinal y con posterior diseminación a sistema nervioso central, bacteriemia, endocarditis o sepsis de origen desconocido. Se ha reportado una incidencia anual de 0,2 y 0,8 casos por 100.000 en Europa y en 
población general de Estados Unidos de América, respectivamente ${ }^{1,8,9}$, con presentación mayor en el género masculino y en primavera y verano ${ }^{6,9}$; en México se desconocen datos epidemiológicos. La infección puede afectar sitios poco frecuentes, como articulaciones, hueso, vesícula y peritoneo ${ }^{1}$, manifestándose esta última como peritonitis bacteriana espontánea (PBE), condición de la cual se han publicado menos de 50 casos, casi todos ellos asociados a cirrosis hepática ${ }^{2-5,10-13}$, o bien en pacientes en diálisis peritoneal ${ }^{14-16}$. Comunicamos el primer caso de peritonitis espontánea por Listeria monocytogenes en México y en América Latina, cuya importancia radica en la necesidad de buscar esta rara pero peligrosa complicación, sobre todo entre los pacientes con compromiso hepático, ya que usualmente no responde al tratamiento convencional de la PBE en base de cefalosporinas, requiriendo, por lo tanto, un tratamiento específico ${ }^{16}$.

\section{Caso CLíNICO}

Historia y antecedentes. Paciente masculino de 31 años de edad, originario y residente de la zona urbana de la ciudad de Colima, México, con antecedente de alcoholismo desde los 16 años de edad y diagnóstico de cirrosis hepática alcohólica nutricional desde un año previo a su ingreso, manejada de forma ambulatoria con espironolactona, propranolol, ranitidina y lactulosa. Su enfermedad actual comenzó dos semanas antes de su último ingreso, con distensión abdominal progresiva y dolorosa, fiebre cuantificada hasta $39^{\circ} \mathrm{C}$, ortopnea y compromiso del estado general.

Examen físico. $\mathrm{Al}$ ingreso el paciente se encontró conciente, bien orientado en tiempo y espacio, presión arterial de 130/70 $\mathrm{mmHg}$, temperatura $38^{\circ} \mathrm{C}$, con hipertrofia de parótidas, atrofia de maseteros, telangiectasias en cara y tórax, además de ginecomastia; a la auscultación de tórax se encontraron signos de hipoventilación con discretos estertores crepitantes húmedos en ambas bases pulmonares; en el abdomen, además de la distensión, se detectaron circulación venosa colateral y dolor generalizado a la palpación profunda, con signos de irritación peritoneal (signo de rebote positivo), así como ascitis. Otros datos clínicos incluyeron vello con distribución ginecoide, atrofia de testículos y moderado edema de miembros inferiores.

Exámenes de laboratorio. Hemograma: hemoglobina de $10 \mathrm{~g} / \mathrm{dL}$, glóbulos blancos $11.000 / \mathrm{mm}^{3}, 83 \%$ de polimorfonucleares, plaquetas $142.000 / \mathrm{mm}^{3}$, albúmina sérica $3,2 \mathrm{~g} / \mathrm{L}$, glicemia $73 \mathrm{mg} / \mathrm{dL}$, urea sérica $52 \mathrm{mg} / \mathrm{dL}$, bilimubina total de $1,94 \mathrm{mg} / \mathrm{dL}$, $(1,22 \mathrm{mg} / \mathrm{dL}$ de bilirrubina directa y $0,72 \mathrm{mg} / \mathrm{dL}$ de indirecta) transaminasa glutámico oxalacética (AST) 48 UI, transaminasa glutámico pirúvica (ALT) 21 UI, fosfatasa alcalina $190 \mathrm{UI} / \mathrm{L}$, tiempo de protrombina de 14" control 12". La radiografía de tórax mostró elevación bilateral de diafragmas y la de abdomen imagen en vidrio esmerilado en forma difusa; un ultrasonido hepático mostró hígado pequeño con imágenes de densidad irregular interpretadas como zonas de fibrosis, discreta dilatación de vena porta y esplenomegalia. La endoscopia reveló várices esofágicas grado II, no sangrantes y gastritis erosiva. Al segundo día de su ingreso, se practicó una paracentesis que mostró un líquido peritoneal de aspecto turbio, amarillento, proteínas de $2,8 \mathrm{~g} / \mathrm{dL}$, células $207 / \mathrm{mm}^{3}$, con $85 \%$ de polimorfonucleares; la tinción de Gram resultó negativa a bacterias, el cultivo se reportó positivo (a las 96 h) para Listeria monocytogenes (sembrado en agar soya tripticasa e identificado con el equipo Autoscan $4^{\circledR}$ [Microscan Dade-Behring, Sacramento Cal]) el patrón de susceptibilidad antimicrobiana mostró que el microorganismo era sensible a ampicilina, ciprofloxacina, gentamicina y resistente a cefalosporinas de tercera generación y a clindamicina.

Evolución hospitalaria. A su ingreso se inició tratamiento empírico con cefotaxima intravenosa, mostrando empeoramiento en las $48 \mathrm{~h}$ posteriores, con incremento de fiebre hasta $40^{\circ} \mathrm{C}$, agregándose deterioro neurológico, con pobre respuesta a estímulos, signo de la rueda dentada, asterixis y temblores generalizados, así mismo desarrolló datos francos de congestión pulmonar e hipotensión arterial $(80 / 40 \mathrm{mmHg})$. Considerando el microorganismo aislado y patrón de susceptibilidad, se cambió esquema a ampicilina y levofloxacina, además de lactulosa oral, furosemida y digoxina. Hubo caída de la fiebre, mejoría de su insuficiencia cardíaca y del estado alerta al cabo de 4 días con el tratamiento señalado. El paciente 
solicitó alta voluntaria a los 9 días de su ingreso, falleciendo 8 días después en su domicilio, al parecer con un cuadro febril, con dolor abdominal y confusión mental.

\section{DISCUSIÓN}

La PBE es una infección que debe ser sospechada en todo paciente con alteración de la inmunidad celular, como es el caso de aquellos con daño hepático avanzado, quienes además presenten datos clínicos sugestivos de infección, como fiebre, que se presenta entre 50 y $70 \%$ de los casos y el dolor abdominal, que afecta entre 30 y $70 \%$ de los pacientes con PBE ${ }^{15,16}$, considerando además, que esta condición es la causa más frecuente de complicación infecciosa en este tipo de pacientes $(96 \%)^{6,17,18}$.

Se ha postulado que la PBE es provocada por un aumento de la permeabilidad intestinal, sumado a edema intestinal secundario a la hipertensión portal, frecuentes en los pacientes con cirrosis hepática. Esto favorece el paso o traslocación de bacterias, desde el lumen intestinal hasta los nódulos linfáticos mesentéricos y de allí a la cavidad peritoneal, sobre todo en presencia de ascitis $^{16}$, este proceso se ve favorecido por la sobreproliferación bacteriana intestinal combinada con disminución de IgA luminal, frecuentemente observadas en esta clase de pacientes ${ }^{9,16}$, motivo por el cual las bacterias que con mayor frecuencia se reportan son bacterias Gram negativas (E coli y Klebsiella spp $)^{4}$. Por otro lado, es común que en los pacientes con cirrosis hepática el almacenamiento de hierro se encuentre elevado, lo que se ha demostrado favorece el crecimiento de L monocytogenes a nivel intestinal $1^{5,9,11}$.

La peritonitis por Listeria monocytogenes, ha sido detectada en varias partes del mundo, pero particularmente en España, en donde se ha encontrado una incidencia inusualmente alta, se ha sugerido que puede estar relacionada a un clima cálido combinado con un mayor consumo de ciertas frutas y vegetales, que podrían provocar una mayor colonización intestinal por esta bacteria $^{2,9,11,12}$. A pesar de que la PBE por L monocito- genes ha sido identificada preferentemente en España, existen informes aislados de esta patología en otros países, lo cual habla de que se trata de un fenómeno cosmopolita. Esta es la primera ocasión que se informa PBE por Listeria monocytogenes en México y, al parecer, en América Latina, aunque es posible que se hayan presentado previamente casos similares y que no hayan sido comunicados. Para el diagnóstico específico es de primordial importancia apoyarse con la identificación bacteriana y su patrón de susceptibilidad a antibióticos, lo que representa una herramienta primordial para el manejo; desafortunadamente en este caso no se determinó serotipo, lo cual hace difícil especular sobre cuál haya sido el origen de la infección, aunque posiblemente ésta fue a través de la ingesta de alimentos contaminados con posterior colonización intestinal, que es la forma más común de inoculación ${ }^{1,3,7}$, considerando que se han hecho aislamientos del germen a partir de diversos tipos de vegetales, quesos y otros productos lácteos y congelados $^{19}$.

A pesar de que esta infección constituye una rareza clínica, es muy importante tenerla en mente, sobre todo en los pacientes cirróticos con cuadro sugestivo de peritonitis, ya que el manejo empírico convencional de la PBE, generalmente a base de cefalosporinas o de quinolonas, suele ser ineficaz para combatir L monocytogenes en donde el tratamiento de primera elección es la ampicilina sola o asociada a un aminoglucosido por 10-14 días $3,4,9,12$; el dejar avanzar una infección de esta naturaleza en pacientes inmunocomprometidos, como aquellos con insuficiencia hepática, conlleva al desarrollo de complicaciones generalmente fatales como meningitis, septicemia o endocarditis con una mortalidad de $28-40 \%$, situación que seguramente se presentó en nuestro paciente al interrumpir el tratamiento intrahospitalario en forma voluntaria ${ }^{9,16,18}$.

Por lo tanto, es importante tener en mente esta etiología en pacientes con daño hepático y datos clínicos o de laboratorio sugestivos de PBE, sobre todo por la necesidad de tratamiento específico diferente al usado convencionalmente en forma empírica. 


\section{REFERENCIAS}

1. Armstrong D. Listeria monocytogenes. En: Mandell GL, Bennett JE, Dolin R, editores. Principles and practice of infectious diseases. New York: Churchill Livingstone Inc; 2004; p. 2108-113.

2. López-CePERo AJM, Benítez-Roldán A. Spontaneous bacterial peritonitis caused by Listeria monocytogenes in a patient with liver cirrhosis. Rev Esp Enferm Dig 2001; 93: 545-6.

3. Adeonigbagbe O, Khademi A, Karowe M, Gualtieri $\mathrm{N}$, RoвiLotTi J. Listeria monocytogenes peritonitis. An unusual presentation and review of the literature. J Clin Gastroenterol 2000; 30: 436-7.

4. Uriarte-Retuerto I, Bujunda-Fernández de Piérola L, Peña-Sarnago P. Peritonitis bacteriana espontánea por Listeria monocytogenes. An Med Interna 2002; 19: 214-5.

5. Tena-Gómez D, Carranza-González R, Pérez-Roldán F. Peritonitis bacteriana espontánea por Listeria monocytogenes. A propósito de un nuevo caso. An Med Interna 2005; 22: 203-4.

6. Qhyyum QJ, Scerpela EG, Moreno JN, Fischl MA. Report of 24 cases of Listeria monocytogenes infection at University of Miami Medical Center. Rev Invest Clin 1997; 49: 265-70.

7. Sснuснат A, Broome CV. Infecciones causadas por Listeria monocytogenes. En: Braunwald E, Fauci AS, Kasper DL, Hauser SL, Longo DL, Jameson JL, editores. Harrison. Principles of internal medicine. México. McGraw-Hill Companies; 2001; p. 1083-6.

8. Castrejón-Alba MM, Mateo-Balmew T, Pérez-MiraVETE A. Meningoencefalitis por Listeria monocytogenes en niños inmunocomprometidos. Bol Med Hosp Infant Mex 1997; 54: 76-80.

9. Arias-Miranda IM, Nuño-Mateo FJ, Noval-MéndeZ J, Fonseca-AizPuRu EM, MenÉndez-CaLderón MJ. Listeriosis en el adulto. Revisión de 10 casos. An Med Interna 2004; 21: 75-8.
10. Polanco A, Giner C, Canton R, León A, GarcíaGonzÁLEZ M, BAQUero F ET al. Spontaneous bacterial peritonitis caused by Listeria monocytogenes: two case reports and literatura review. Eur J Clin Microbiol Infect Dis 1992; 11: 346-9.

11. Vázquez J, Such J, Ena J, Arguelo L, Ortiz V, Mongot M ET AL. Spontaneous bacterial peritonitis caused due to Listeria monocytogenes. Rev Esp Enferm Dig 1995; 87: 407-11.

12. Jorquera-Plaza F, Espinel-Diez J, Fernández-Gundin MJ, Munoz-Nunez F, HerRera-Abian A, Vivas-Aleggre $S$ ET AL. Spontaneous bacterial peritonitis caused by Listeria monocytogenes. Gastroenterol Hepatol 1998; 21: 489-91.

13. Nolla-Salas J, Almela M, Gasser I, Latorre C, Salvado M, Coll P. Spontaneous Listeria monocytogenes peritonitis: a population-based study of 13 cases collected in Spain. Am J Gastroenterol 2002; 97: 1507-11.

14. Pérez-Roldán F, Banares R, Piqueras B, De-Diego A, Castelote I, Casado M et al. Spontaneous bacterial peritonitis caused by Listeria monocytogenes. Rev Esp Enferm Dig 1995; 87: 889-92.

15. Baños-González M, Cerda-Télezz $F$, Lozano-Nuevo JJ, RuBio-GuerRa AF. Microorganismo más frecuente causante de peritonitis en pacientes con insuficiencia renal crónica secundaria a nefropatía diabética, con diálisis peritoneal continua ambulatoria. Med Int Mex 2004; 20: 325-8.

16. SHEER TA, RuNYon BA. Spontaneous bacterial peritonitis. Dig Dis 2005; 23: 39-46.

17. Kaplan Je, Rosele G, Sepkowitz K. Opportunistic infections in immunodeficient populations. Em Infect Dis 1998; 4: 421-2.

18. Doganay M. Listeriosis: clinical presentation. FEMS Immunology and Medical Microbiology 2003; 35: 173-5.

19. Monge R, ARia-Echandi ML. Presence of Listeria monocytogenes in fresh salad vegetables. Rev Biomed 1999; 10: 29-31.

Agradecimiento

A Jennifer Unrau, alumna de la Facultad de Medicina de la Universidad de Colima por su valiosa colaboración en la traducción del resumen. 